\title{
Global digital image correlation up to very high temperatures with grey level corrections
}

\author{
Thibaut ARCHER ${ }^{\mathrm{abc}}$, Pierre BEAUCHÊNEa ${ }^{\mathrm{a}}$, Cédric HUCHETTEa ${ }^{\mathrm{a}}$, \\ François HILD
}

aONERA, 29 avenue de la Division Leclerc, 92320 Châtillon, France bSAFRAN Ceramics, a technology platform of Safran Tech, Mérignac, France 'LMT (ENS Paris-Saclay / CNRS / Université Paris-Saclay), 61 avenue du Président Wilson, 94235 Cachan, France

\begin{abstract}
The characterisation of high temperature materials for extreme environment implies experimental challenges. Displacement measurements using Digital Image Correlation (DIC) have proven to be an efficient non-contact method even at high temperatures. This paper uses global DIC and grey level corrections to analyse very high temperature tests in which inversion of the grey level distribution may occur. The benefits of grey level corrections are shown on a coated ceramic matrix composite heated up to $1400^{\circ} \mathrm{C}$. The inversion of the grey level distribution is then accounted for to study various ceramics subjected to temperatures up to $1860^{\circ} \mathrm{C}$.
\end{abstract}

Keywords: Global DIC, very high temperatures, grey level relaxation 


\section{Introduction}

The development of high temperature materials for challenging environments (e.g. aerospace or aircraft engines) implies high temperature characterisations [14]. To fully determine the thermomechanical behaviour, various non-contact fullfield measurement techniques [5] are used. DIC is one possible route, which is efficient for room temperature [6] but also in high temperature tests. The work of Lyons et al. [7], where the authors successfully tested specimens experiencing rigid body translation, thermal expansion and tensile load up to $650^{\circ} \mathrm{C}$, showed the feasibility of DIC at those temperature levels. Liu et al. [8] managed to study creep crack growth in nickel-based superalloy up to $700^{\circ} \mathrm{C}$. Pan et al. [9] and Grant et al. [10] reported reliable DIC measurements up to $1200^{\circ} \mathrm{C}$. Leplay et al. [11] performed DIC at $1350^{\circ} \mathrm{C}$ to quantify the asymmetric creep behaviour of an industrial zircon ceramic. Novak and Zok [12] extended the use of DIC up to $1500^{\circ} \mathrm{C}$ by filtering thermal radiations and reducing heat haze effects. Last, Wang et al. [13] managed to reach temperatures up to $2000^{\circ} \mathrm{C}$ in vacuum chamber.

Because of thermal radiations, brightness conservation is no longer strictly satisfied. The afore-mentioned works proposed experimental solutions using powerful lighting with band pass filters $[9,10,12]$ to mitigate these radiation effects, or working at shorter wavelengths [14] as suggested by Planck's law. It is worth noting that grey level correction is also one possible route that was followed for local DIC [6], and more recently in global approaches $[15,16]$.

All these works also highlight some critical points about DIC analyses performed at high temperatures:

- Grey level distributions were preserved using high temperature black and white paints up to $1100^{\circ} \mathrm{C}$. At higher temperatures, the oxidation of the 
coatings caused contrast loss. Nitride and aluminium oxides were used [7], but also cobalt oxide mixed with inorganic adhesive [9].

- Thermal gradients between the hot sample surface and ambient air generate variations of the refractive index, and thus artefacts for the optical path. This heat haze effect was limited using forced air flux $[7,12]$. Furnaces are probably the worst case $[7,11]$, as a large amount of air is concerned, except when fans were used [11]. Spatiotemporal DIC approaches [4] enable these effects to be mitigated.

The aim of this paper is to understand as quantitatively as possible the brightness and contrast changed as functions of temperature, and to show the feasibility of global DIC up to very high temperatures (i.e. greater than $1800^{\circ} \mathrm{C}$ ) without powerful LED lighting at short wavelength as usually performed. Global (e.g. FE-based) DIC was introduced to allow more direct interactions with numerical simulations by sharing the same kinematic bases [17]. The fact that the continuity of the displacement field is ensured a priori enabled the measurement uncertainties to be decreased in comparison to local analyses in which the node connectivities were not accounted for [18]. Grey level corrections have been thoroughly studied for local DIC [6]. However, even though the general framework was already introduced [19], it was seldom utilized since in many laboratory tests the illumination was stable enough to enable the hypothesis of brightness conservation to be made. In the cases analysed hereafter, such hypothesis was not satisfied and it called for the relaxation of this condition. It is worth noting that some applications already required grey level corrections to be performed (e.g., registration of infrared pictures [20] and distortion corrections of IR lenses [16]).

The outline of the paper is as follows. First, the tested materials, experimental setup and acquisition system are presented with a detailed part on 
the description of contrast variation at high temperatures based on filtering thermal radiation and illumination. Global DIC is then introduced with corrections for grey level variations. Last, a coated ceramic matrix composite heated up to $1400^{\circ} \mathrm{C}$ is studied, and various ceramics heated over $1500^{\circ} \mathrm{C}$ where an inversion of the grey level distribution is introduced to perform DIC.

\section{Materials and methods}

\subsection{Tested materials}

A coated ceramic matrix composite was first tested. Such materials are currently under development for future gas turbine engines, and may provide fuel efficiency and better performance by increasing the operating temperature because of their good physical properties at very high temperatures and their low density [21-24]. The heated surface was an environmental barrier coating (EBC) made of yttrium disilicates. The investigated temperature was up to $1400^{\circ} \mathrm{C}$. To move beyond the former limit, monolithic ceramics were selected. An alumina sample was first heated, then a hafnia-based material, which is currently investigated for spacecraft propulsion [29], was tested up to $1860^{\circ} \mathrm{C}$.

\subsection{Experimental setup}

Figure 2.1 shows a schematic description of the experimental setup. The heating source was a $3 \mathrm{~kW} \mathrm{CO}$ laser operating at a wavelength of $10.6 \mu \mathrm{m}$. The beam had the shape of a Gaussian profile. Yet it can be homogenised using various optics to obtain a nearly uniform (i.e. top-hat) heat flux. To reduce heat haze effects, a small fan was positioned $40 \mathrm{~cm}$ from the sample, thereby creating forced laminar flow [12]. 


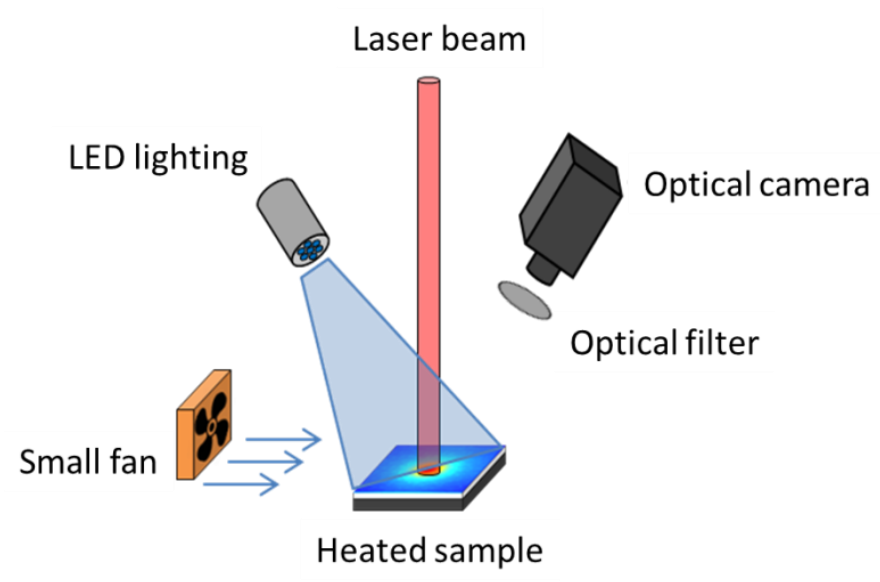

FIGURE 2.1: Schematic description of the experimental setup

The quantum efficiency of the camera used in this work is plotted in Figure 2.2 and shows that the detector can be combined with the optical filter, the idealized transmissivity of which is shown in Figure 2.3 to capture images at shorter wavelengths. The hardware parameters of the optical setup are reported in Table 1.

TABLE 1: DIC hardware parameters

\begin{tabular}{cc}
\hline Camera & AVT PIKE F-421 (monochrome detector) \\
\hline Camera definition & $2048 \times 2048$ pixels \\
\hline Filter & Schneider Kreuznach Band pass Filter, $465-70 \mathrm{HT}$ \\
\hline Grey Levels amplitude & 8 bits \\
\hline Lens & See text \\
\hline Field of view & see text \\
\hline Image scale & 1 fps \\
\hline Image acquisition rate & see text \\
\hline Exposure time & \\
\hline
\end{tabular}




\begin{tabular}{cc}
\hline Stand-off distance & $26 \mathrm{~cm}$ \\
\hline Patterning technique & SiC powder \\
\hline Pattern feature size & 12 pixels in diameter \\
\hline
\end{tabular}

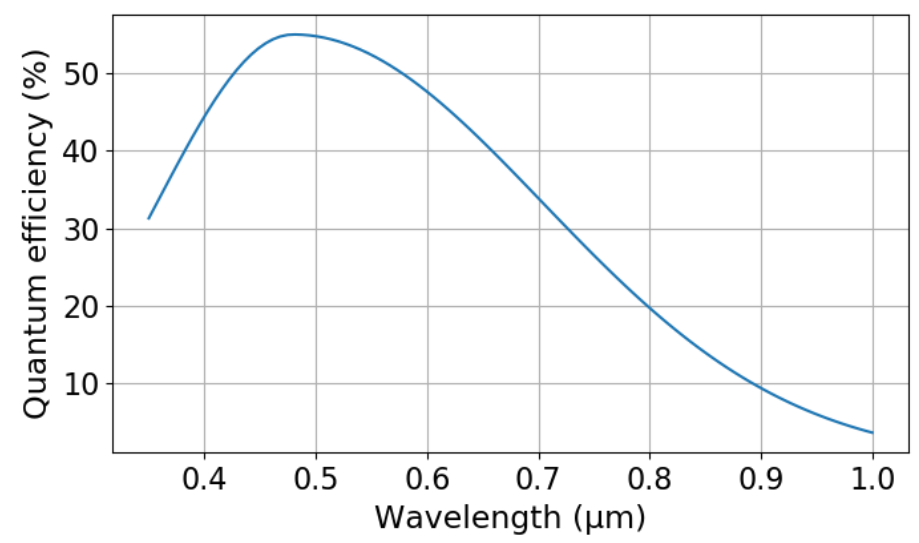

FIGURE 2.2: Quantum efficiency of the camera sensor used herein

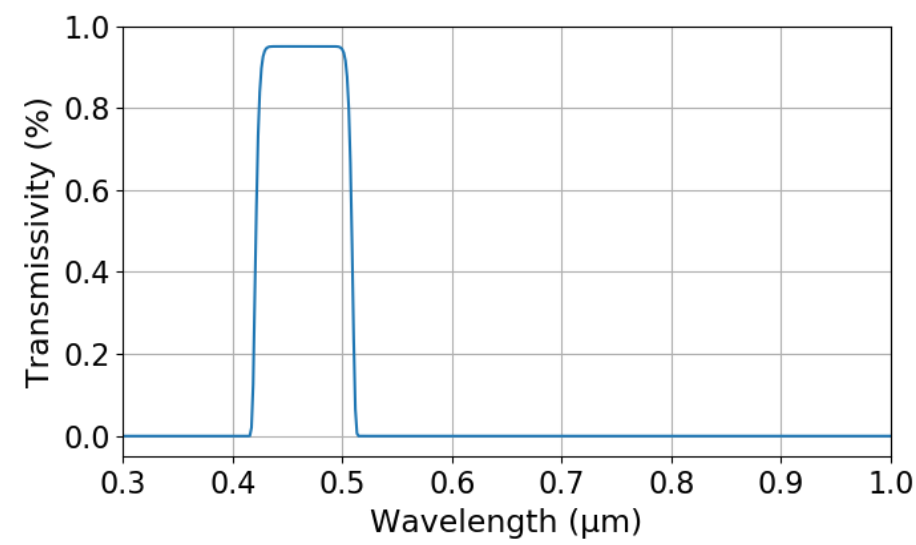

FiguRE 2.3: Spectral response of optical filters

The LED lighting device was made of 2 matrices with 7 LEDs each (Luxeon Rebel, LXML-PR01-0500). Each LED provided $520 \mathrm{~mW}$ in standard use, making the total radiometric power equal to about $7.3 \mathrm{~W}$. The distribution of power of LED lighting $I_{L E D}(\lambda)$ reads 


$$
I_{L E D}(\lambda)=\frac{P_{t o t} I_{r e l}(\lambda)}{\pi\left(0.01+z \tan \left(\frac{\beta}{2}\right)\right)^{2} \int_{\lambda_{1}}^{\lambda_{2}} I_{r e l}(\lambda) d \lambda}
$$

where $P_{\text {tot }}$ is the total power of LED lighting, $I_{\text {rel }}(\lambda)$ the relative intensity of LED lighting with a maximum at $100 \%, z$ the sample stand-off distance, and $\beta$ the angle of the lens that is used to direct the light.

Last, to produce a speckle able to sustain temperatures above $1300^{\circ} \mathrm{C}$, powders were used instead of coatings because of their lack of durability at these levels [26]. As all the substrates tested in this work are light, silicon carbide (SiC) powder was selected for its dark colour, and was deposited onto the sample with a sieve. An example of speckle pattern is shown in Figure 2.4.

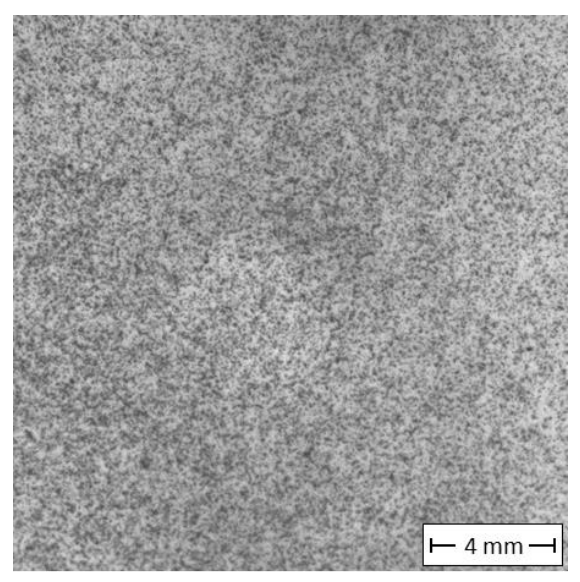

FIGURE 2.4 : Speckle obtained using SiC powders on white substrate

\subsection{Contrast changes at high temperatures}

To estimate the feasibility of DIC, it is essential to compare the emitted light (because the samples are heated) and the reflected light (due to lighting). One advantage of using powders on the surface and not a mixture of black and white paints is that the contribution of each material are assessed separately. Previous works $[10,11]$ have defined these two contributions acquired by the camera, 
sometimes by assuming simplified optical properties [27]. The emitted light $I_{E}$ is determined from Planck's law

$$
I_{E}(T)=\int_{\lambda_{1}}^{\lambda_{2}} \varepsilon(\lambda, T) E(\lambda) t(\lambda) \frac{2 h c^{2}}{\lambda^{5}\left(e^{\frac{h c}{\lambda k T}}-1\right)} d \lambda
$$

where $\varepsilon(\lambda, T)$ is the emissivity of the surface depending on the wavelength $\lambda$ and the temperature $T, E(\lambda)$ the quantum efficiency of the detector, $t(\lambda)$ the transmissivity of the optical filter(s), $h$ Planck's constant, $c$ the speed of the light and $k$ Boltzmann's constant. The contribution of the reflected light from the lighting source reads

$$
I_{R}(T)=\int_{\lambda_{1}}^{\lambda_{2}} \rho(\lambda, T) E(\lambda) t(\lambda) I_{L E D}(\lambda) d \lambda
$$

where $\rho(\lambda, T)$ is the coefficient of reflection of the material.

At this stage, a distinction should be made depending on the material. Let us consider the substrate material and $\mathrm{SiC}$ powder. It is assumed that the heated material is opaque (transparency measurements were conducted on the environmental barrier coating (EBC) studied in the next section) and the size of the powder grains is uniform.

By adjusting the exposure time of the camera, contrast changes are defined in a generic way as

$$
C(T)=\frac{\left(I_{E, S i C}(T)+I_{R, S i C}(T)\right)-\left(I_{E, E B C}(T)+I_{R, E B C}(T)\right)}{\max \left(\left(I_{E, E B C}(T)+I_{R, E B C}(T)\right),\left(I_{E, S i C}(T)+I_{R, S i C}(T)\right)\right)}
$$


where the numerator is the difference of the contributions (emitted and reflected light) for each material and the denominator the maximum contribution because, experimentally, the exposure time will be adjusted on the lighter material. This derivation is used to estimate the capacity of the acquisition system to perform DIC for different temperature ranges, and to anticipate brightness and contrast changes, and possibly inversions.

\subsection{Global DIC procedure with grey level corrections}

One advantage of global DIC is to consider the minimisation of the grey level residuals over the whole region of interest (ROI), thereby ensuring the continuity of the displacement field that is assumed to be true in most of the present cases. Let us define $f$ the grey level image in the reference configuration, and $g$ that in the deformed configuration. When the grey level conservation is fully satisfied (i.e. with no image noise), $g$ is related to $f$ by

$$
g(x+u(x))=f(x)
$$

where $\boldsymbol{x}$ is any pixel in the ROI, $\boldsymbol{u}(\boldsymbol{x})$ the sought displacement field. For several reasons, such as over-exposition, lighting fluctuations the grey level conservation may be violated (see previous section). It is still possible to perform DIC $[16,19,28]$ with an affine transformation of the grey level scale. In that case, the corrected reference image $\hat{f}$ is defined as

$$
\hat{f}(\boldsymbol{x})=f(\boldsymbol{x})+a(\boldsymbol{x})+b(\boldsymbol{x}) f(\boldsymbol{x})
$$

where $a(\boldsymbol{x})$ is the brightness correction, and $b(\boldsymbol{x})$ the contrast correction. Let $\tilde{g}_{u}$ denote the picture of the deformed configuration corrected by the measured displacement 


$$
\tilde{g}_{u}(\boldsymbol{x})=g(\boldsymbol{x}+\boldsymbol{u}(\boldsymbol{x}))
$$

The goal of the correlation procedure is to find $\boldsymbol{u}, a$ and $b$ that minimize the squared norm of residuals $\eta$ defined as

$$
\eta(\boldsymbol{x})=\hat{f}(\boldsymbol{x})-\tilde{g}_{u}(\boldsymbol{x})
$$

Because the previous problem is ill-posed, it needs to be regularized. The fields $\boldsymbol{u}, a$ and $b$ are decomposed over suited bases

$$
\begin{aligned}
& \boldsymbol{u}(\boldsymbol{x})=\sum_{\boldsymbol{i}} u_{i} \boldsymbol{\theta}_{\boldsymbol{i}}(\boldsymbol{x}) \\
& a(\boldsymbol{x})=\sum_{\boldsymbol{p}} a_{p} \varphi_{p}(\boldsymbol{x}) \\
& b(\boldsymbol{x})=\sum_{\boldsymbol{p}} b_{p} \varphi_{p}(\boldsymbol{x})
\end{aligned}
$$

where $\boldsymbol{\theta}_{\boldsymbol{i}}, \varphi_{p}$ are shape functions, and $u_{i}, a_{p}, b_{p}$ the amplitudes to determine, which are gathered in vectors $\{\boldsymbol{u}\}$ and $\{\boldsymbol{c}\}$. In the following, in order to avoid the coupling between displacements and grey level corrections, a sequential minimization is carried out. The first step, on the displacements, updates the vector $\{\boldsymbol{u}\}$ (at fixed correction fields) that minimizes the squared norm of residuals $\eta_{u}$ defined as

$$
\eta_{u}(\boldsymbol{x})=\hat{f}(\boldsymbol{x})-g(\boldsymbol{x}+\boldsymbol{u}(\boldsymbol{x}))
$$

over the whole ROI $\Omega$ 


$$
\rho_{u}=\sum_{\Omega} \eta_{u}(\boldsymbol{x})^{2}
$$

A Newton-Raphson (iterative) procedure [29] is implemented to solve for the minimization of the linearized grey level residuals, which leads to linear systems in terms of displacement corrections $\{\delta \boldsymbol{u}\}$

$$
\left[\boldsymbol{H}^{\boldsymbol{u}}\right]\{\delta \boldsymbol{u}\}=\left\{\boldsymbol{b}^{\boldsymbol{u}}\right\}
$$

where the components of the Hessian and Jabobian read

$$
\begin{aligned}
H_{i j}^{u} & =\sum_{\Omega}\left(\boldsymbol{\nabla} \hat{f} \cdot \boldsymbol{\theta}_{i}\right)(\boldsymbol{x})\left(\boldsymbol{\nabla} \hat{f} \cdot \boldsymbol{\theta}_{j}\right)(\boldsymbol{x}) \\
b_{i}^{u} & =\sum_{\Omega}\left(\boldsymbol{\nabla} \hat{f} \cdot \boldsymbol{\theta}_{i}\right)(\boldsymbol{x})\left(\hat{f}-\tilde{g}_{u}\right)(\boldsymbol{x})
\end{aligned}
$$

and $i, j$ are the indices associated with the set of shape functions describing the displacement field.

The second step, which updates the correction fields (at fixed displacement field), evaluates the vector $\{\boldsymbol{c}\}$ that minimizes the squared norm of residuals $\eta_{c}$

$$
\eta_{C}(\boldsymbol{x})=a(\boldsymbol{x})+b(\boldsymbol{x}) f(\boldsymbol{x})+f(\boldsymbol{x})-\tilde{g}_{u}(\boldsymbol{x})
$$

The linear system to solve becomes

$$
\left[\boldsymbol{H}^{c}\right]\{\boldsymbol{c}\}=\left\{\boldsymbol{b}^{c}\right\}
$$

with 


$$
\left[\boldsymbol{H}^{c}\right]=\left[\begin{array}{ll}
{\left[\boldsymbol{H}^{a a}\right]} & {\left[\boldsymbol{H}^{a b}\right]} \\
{\left[\boldsymbol{H}^{b a}\right]} & {\left[\boldsymbol{H}^{b b}\right]}
\end{array}\right]
$$

and

$$
\left\{\boldsymbol{b}^{c}\right\}=\left\{\begin{array}{l}
\left\{\boldsymbol{b}^{\boldsymbol{a}}\right\} \\
\left\{\boldsymbol{b}^{b}\right\}
\end{array}\right\}
$$

where

$$
\begin{gathered}
H_{p q}^{a a}=\sum_{\Omega} \varphi_{p}(\boldsymbol{x}) \varphi_{q}(\boldsymbol{x}) \\
H_{p q}^{a b}=H_{p q}^{b a}=\sum_{\Omega} \varphi_{p}(\boldsymbol{x}) \varphi_{q}(\boldsymbol{x}) f(\boldsymbol{x}) \\
H_{p q}^{b b}=\sum_{\Omega} \varphi_{p}(\boldsymbol{x}) \varphi_{q}(\boldsymbol{x}) f^{2}(\boldsymbol{x}) \\
b_{p}^{a}=\sum_{\Omega}\left(\varphi_{p}(\tilde{g}-f)\right)(\boldsymbol{x}) \\
b_{p}^{b}=\sum_{\Omega}\left(\varphi_{p} f(\tilde{g}-f)\right)(\boldsymbol{x})
\end{gathered}
$$

and $p$ and $q$ are the indices associated with the shape functions of the correction fields.

The global minimisation is conducted by alternatively updating

$$
\{c\}^{k+1}
$$

and then

$$
\{\boldsymbol{u}\}^{k+1}=\{\boldsymbol{u}\}^{k}+\{\delta \boldsymbol{u}\}
$$


This two-step procedure allows $\hat{f}(\boldsymbol{x})$ and $\tilde{g}(\boldsymbol{x})$ to be updated sequentially until the maximum level of the absolute displacement corrections is less than $10^{-4}$ pixel. Such staggered algorithm departs from original implementations $[16,19,20]$, and is identical to the DVC analyses developed for differentiating 3D textile composites [28]. Table 2 summarizes the DIC parameters used in this work.

TABLE 2: DIC analysis parameters

\begin{tabular}{cc}
\hline DIC software & Correli 3.0 $[30]$ \\
\hline Image filtering & none \\
\hline Element length & see text \\
\hline Shape functions & linear (T3) \\
\hline Mesh & regular \\
\hline Matching criterion & see text \\
\hline Interpolant & see text \\
\hline Displacement noise-floor & derivative of shape functions
\end{tabular}

\section{Results}

\subsection{Environmental barrier coating heated up to $1380^{\circ} \mathrm{C}$}

Section 2.3 showed the importance of optical properties. Consequently, emissivity measurements were conducted on an environmental barrier coating by CEMHTI (Orléans, France) [31, 32]. The results are plotted in Figure 3.1. Even if the range of measured wavelengths was not exactly those of the optical camera because of detector sensitivity, the emissivity below a wavelength of 1 um is less 
than 0.3 , in particular at high temperatures. The emissivity of $\mathrm{SiC}$ was studied in other works [33] and is generally high (i.e. greater than 0.8 ).

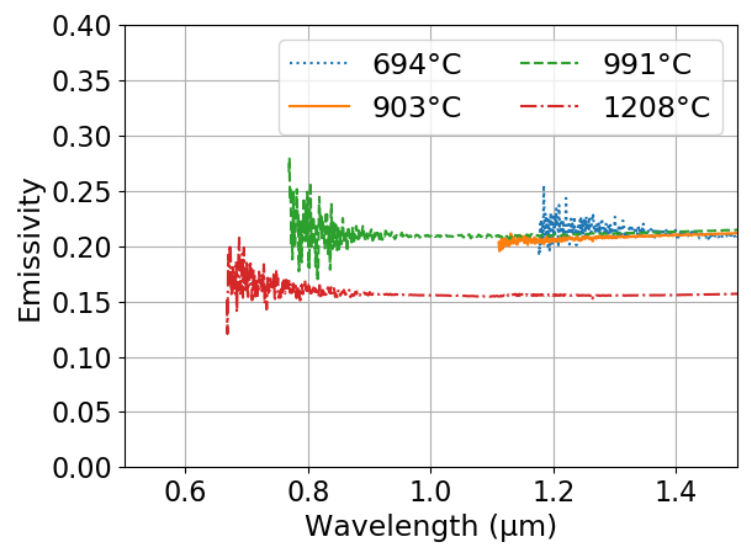

FIGURE 3.1: Emissivity measurements on the EBC studied at short wavelengths

According to Equation (4), the contrast change is plotted in Figure 3.2, as a function of the temperature of the sample surface. For this configuration, the emissivity of the $\mathrm{SiC}$ powder is equal to 0.8 , and that of the environmental barrier coating 0.3. Both values are considered independent of temperature. The power delivered by the lighting device was equal to $7.3 \mathrm{~W}$. This curve is designated as "Ref.". The value of the steady state level is related to the difference of emissivity between the two materials. With the present set of parameters, beyond $1250^{\circ} \mathrm{C}$, the contrast starts to decrease because the fraction of emitted light becomes greater than that of the reflected light. 


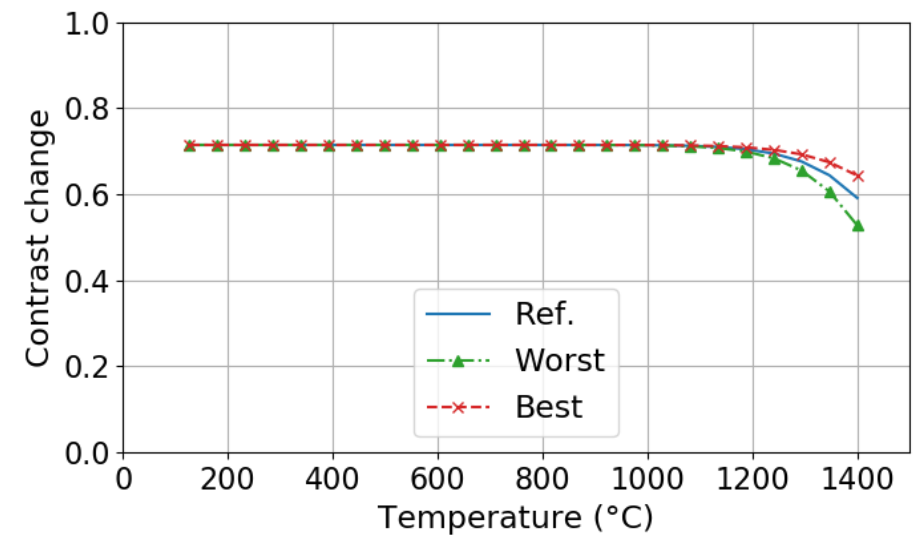

FIGURE 3.2: Theoretical grey level changes as functions of temperature for three different sets of parameters (see text)

To confirm this result, experimental uncertainties must be taken into account. First, if the camera and the optical filter are well known, the LED lighting power represents a large source of uncertainty. The two dotted lines plotted in Figure 3.2 depict idealized ('Best') and critical ('Worst') cases. The power of lighting is varied $20 \%$, according to the manufacturer datasheet the upper (460nm) and lower (440nm) bounds of the LED wavelength are considered, and the sample is brought closer and moved away from the light by $10 \%$.

Last, constant emissivities correspond to an idealized case that is usually sufficient to assess contrast changes. To study the sensitivity on the difference of emissivity between the two materials, two additional cases of contrast fluctuations are reported in Figure 3.3. 'Case 2' corresponds to an increase of 0.05 of the difference in emissivity, and 'Case 3' to a decrease of the same value. The results show that the temperature at which the contrast starts to decrease is not affected by changes in emissivity but also that small variations may occur even at lower temperatures. 


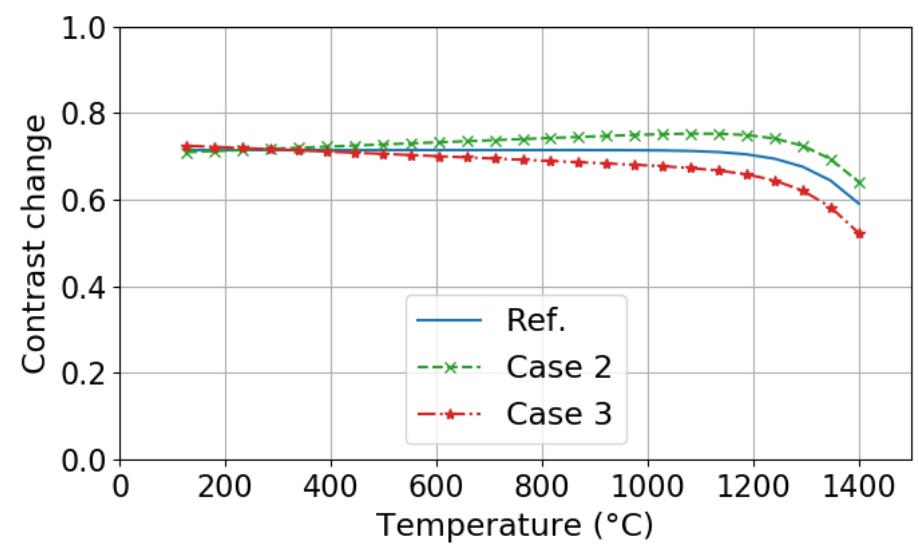

FigURE 3.3: influence of variable emissivities on contrast changes

This part shows the capability of the present system to perform DIC up to high temperatures (i.e. $1300-1400^{\circ} \mathrm{C}$ ) with only small changes of contrast below $1200^{\circ} \mathrm{C}$. However, these changes may impact the measurements as it will be demonstrated. To take them into account, grey level relaxation is the route that is used in the sequel.

The tested $\mathrm{EBC}$ was heated up to $1380^{\circ} \mathrm{C}$. For this acquisition, the resolution was $9 \mu \mathrm{m} /$ pixel, the field of view was $18.4 \times 18.4 \mathrm{~mm}^{2}$ and the exposure time was $20 \mathrm{~ms}$. Surface temperatures were first measured without the $\mathrm{SiC}$ powder thanks to a middle wave infrared camera (FLIR X6580sc) and a twocolour pyrometer to obtain reference values on the raw sample surface. The second heating of the studied sample was conducted with the same temperature history monitored by the two-colour pyrometer. The laser beam had a Gaussian shape and heated up only the centre of the sample (Figure 3.4(b)). One hundred cycles were performed with a temperature profile at the centre of the sample illustrated in Figure 3.4(a). 


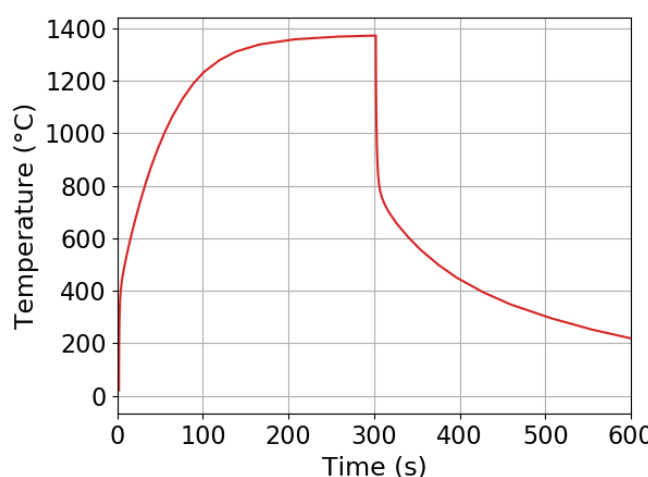

(a)

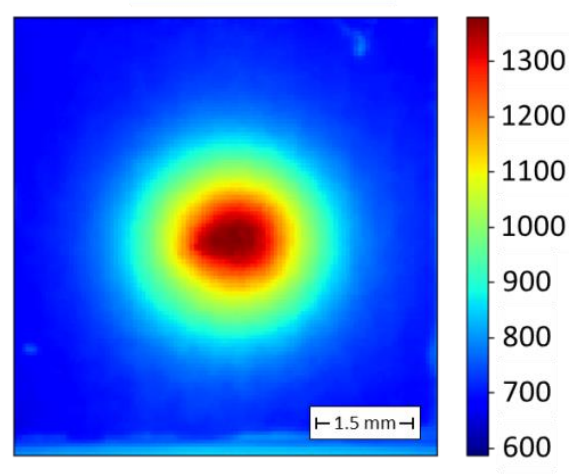

(b)

FIGURE 3.4: (a) Maximum temperature profile of one cycle, and (b) temperature field at the end of the heating step (300 s)

DIC was performed for the last cycle to study the influence of grey level variations. The reference image, considered prior the last heating cycle $(0 \mathrm{~s}$, see Figure 3.4(a)), and that at the end of the heating phase (300 s, see Figure 3.4(a)) are shown in Figure 3.5.

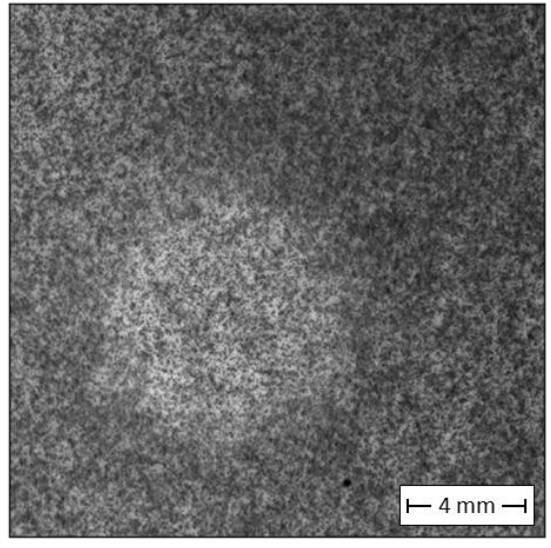

(a)

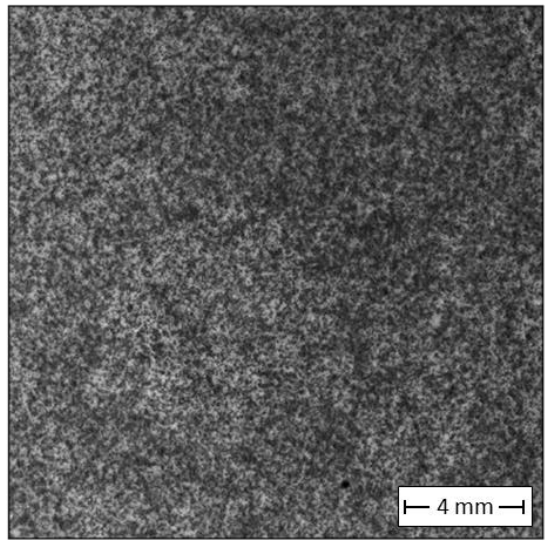

(b)

FIGURE 3.5: (a) Reference and (b) image at the end of the heating phase 
The meshes used to compute the displacement field and the grey level corrections were different. The first one was finer (the average size of one element was $11 \mathrm{px}$ ) to capture high displacement gradients whereas the second one was used to correct brightness and contrast variations and did not require a very fine discretisation (40 px). In Figure 3.6, the RMS grey level residuals (i.e. $\operatorname{RMS}(\eta)$ ) over the ROI are plotted for 40 pictures during one cycle and for several registration procedures: (1) no grey level correction, (2) brightness correction, (3) contrast correction, (4) brightness and contrast corrections.

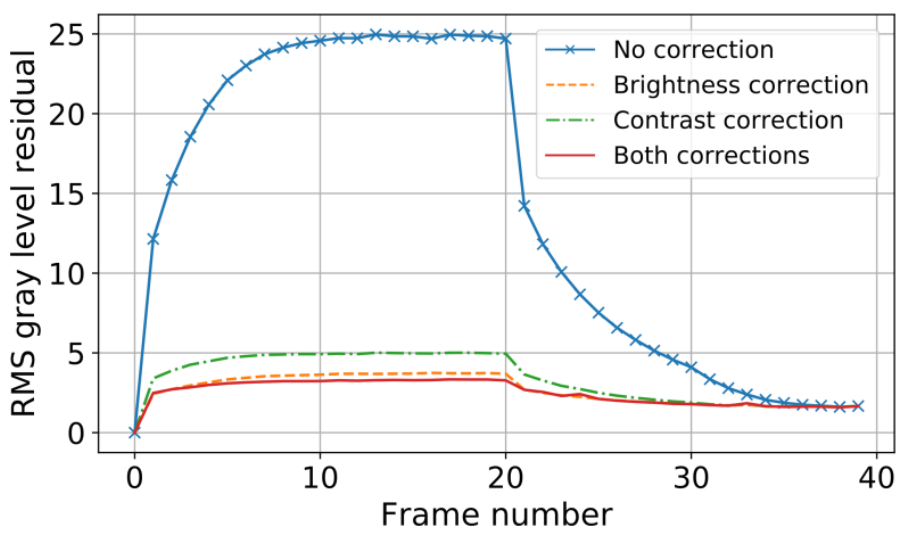

FIGURE 3.6: RMS grey level residual during one cycle for different grey level corrections in DIC analyses

At the end of the heating phase, the residuals with no correction were much higher than those for the other three procedures. This observation proves the benefit of performing grey level corrections. In the latter cases, brightness corrections were more effective than contrast corrections. Brightness and contrast corrections exhibited similar results as brightness corrections alone. These results are explained by the size of the mesh and the fraction of each material in one element. The grey level changes of $\mathrm{SiC}$ powder and $\mathrm{EBC}$ are opposite when the temperature rises, which makes contrast (i.e. gradient) corrections less effective 
for large elements with very thin texture (SiC powder). The brightness correction provides only an offset to the grey levels, which means that the correction follows the change of the material with the biggest fraction in the element (in this case $\mathrm{EBC})$ and weights the value by fraction of the other one.

Last, it is worth noting that the global trend of each curve followed the maximum temperature profile, meaning that the optical camera was sensitive to temperature variations. To confirm that observation, the maximum absolute value of the brightness field for procedure (2) (i.e. brightness corrections alone) is plotted as a function of the profile of maximum temperatures during the heating phase in Figure 3.7. It is shown that the brightness correction may be used as a way of measuring temperature fields, and thus measuring both displacement and temperature fields using a single camera [15].

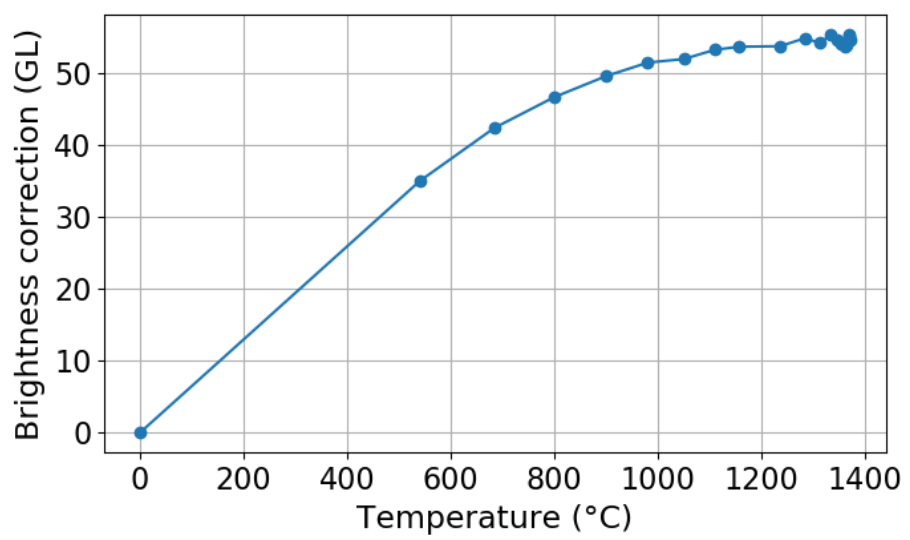

FIGURE 3.7: Maximum brightness correction as a function of maximum temperature during heating

Figure 3.8 shows the displacement field in the horizontal direction and the grey level residual at the end of the heating phase with no correction. There are fluctuations, particularly in the centre of the picture, which coincide with high residuals in that area (up to 78 grey levels). 

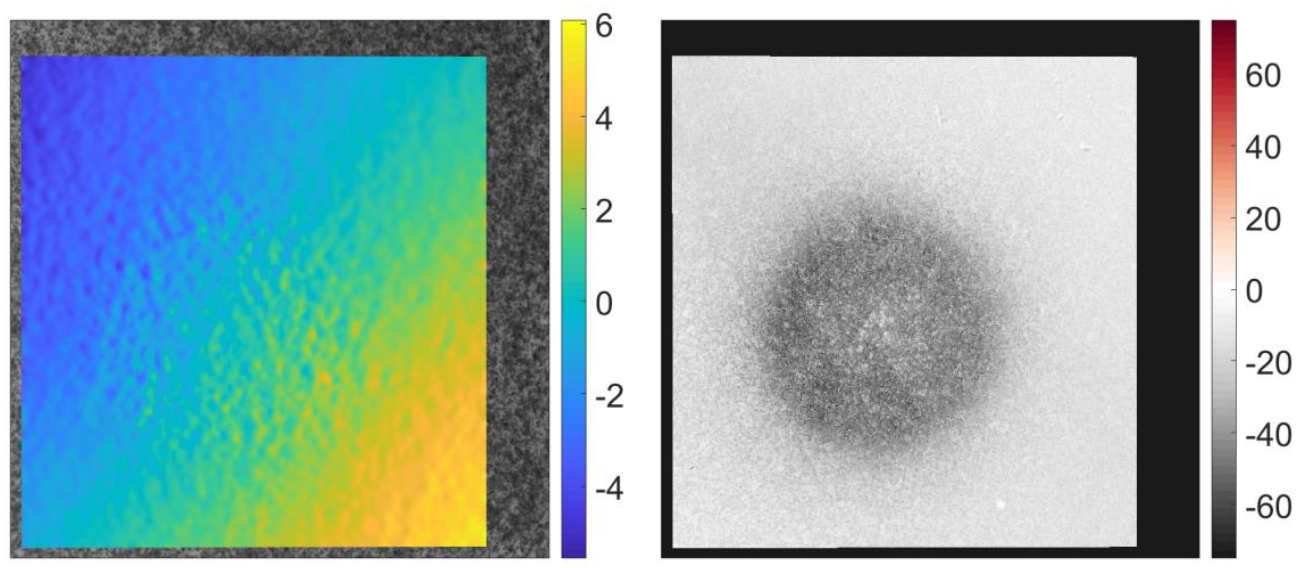

(a)

(b)

FigURE 3.8: (a) Displacement field in the horizontal direction (px) with no correction, and (b) corresponding grey level residual field

In Figure 3.9, the results are shown for a DIC analysis with brightness correction using a coarse mesh. The displacement field (Figure 3.9(a)) fluctuates less with the brightness correction (Figure 3.9(b)) in comparison with the previous result (Figure 3.8). Besides, the mean value of the displacement is almost the same as illustrated on the difference between the previous and the present cases (Figure 3.9(c)). However, the RMS difference is equal to $0.36 \mathrm{px}$, which is higher than the measurement uncertainty $(0.07 \mathrm{px})$. Last, the grey level residuals after correction (Figure 3.9(d)) are significantly lower with an RMS of 4 grey levels (as opposed to 25 grey levels with no corrections). These results prove the benefit of grey level corrections for DIC at very high temperatures. 

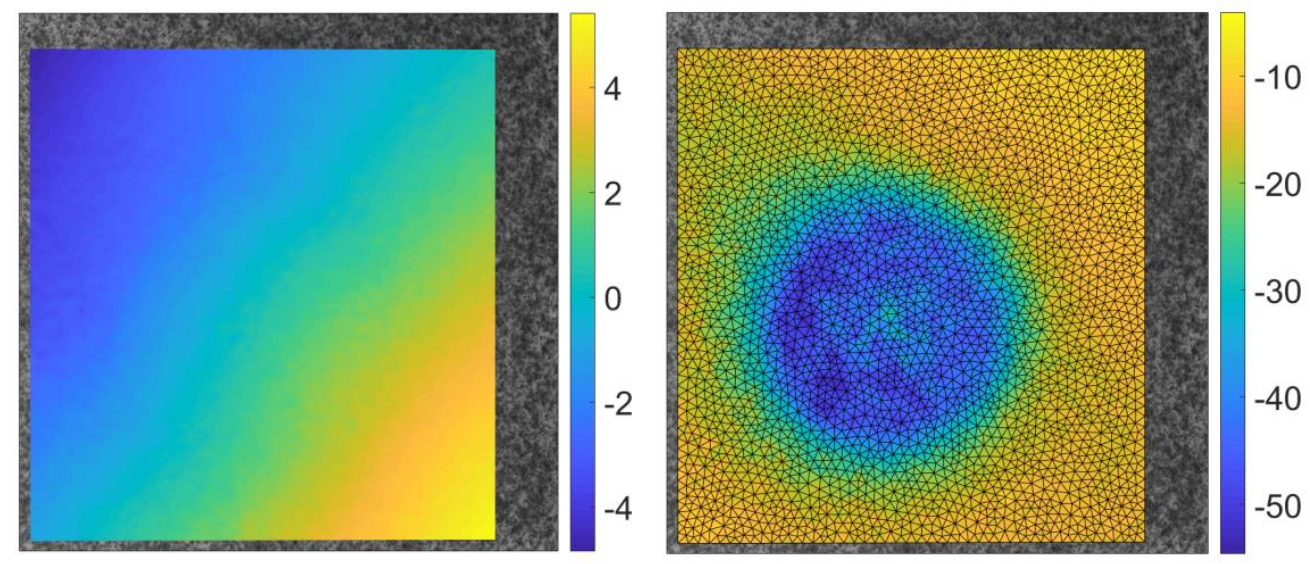

(a)

(b)
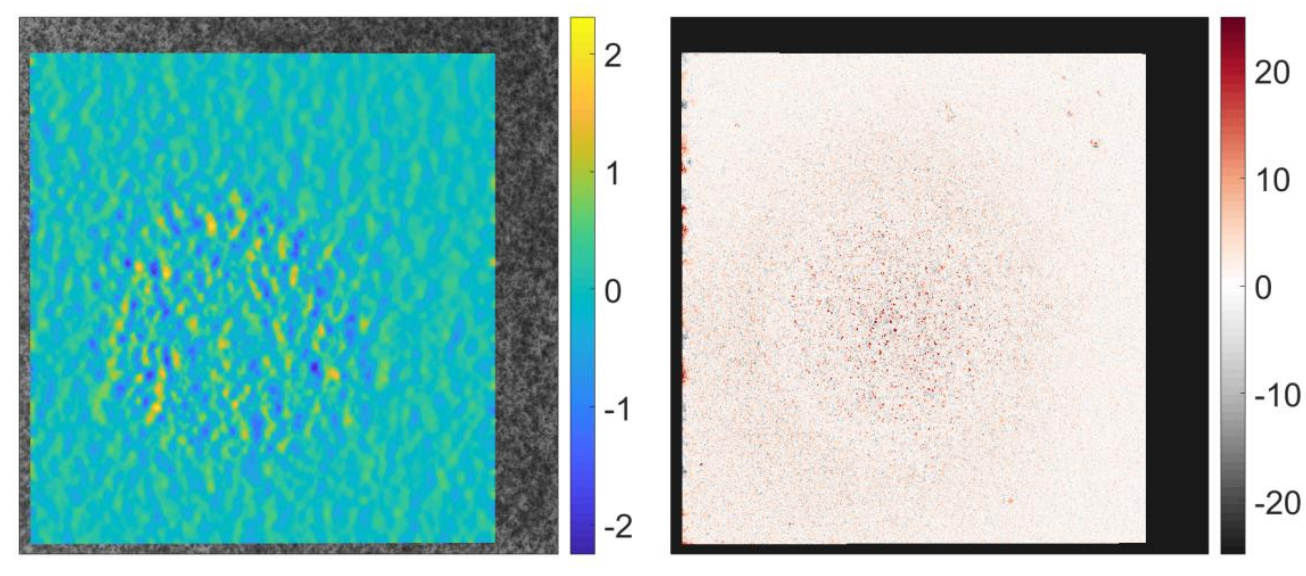

(c)

(d)

FiguRE 3.9: (a) Displacement field in the horizontal direction (px) with brightness correction, (b) brightness correction field (in grey levels), (c) displacement difference with no correction and brightness correction (px), and (d) grey level residual field with a reduced dynamic range than in FIGURE 3.8

Prior to this reference test, a pre-test was performed with only one block of LEDs, far from the sample surface (approximately $30 \mathrm{~cm}$ ). The theoretical response according to Equation (4) is shown in Figure 3.10, labelled as 'Second 
test' and compared to the reference case. Because of the ratio between emitted and reflected intensities, an inversion of contrast is predicted with a range of temperatures $\left(1100-1300^{\circ} \mathrm{C}\right)$ in which contrast is lost. It is worth remembering that the grey levels in the two plateaus are linked to the difference of emissivities between the two materials. Besides, if there is any variation of one emissivity as a function of temperature on one plateau, there is no reason why the grey levels should be identical at room temperature and at high temperatures as shown in Figure 3.3.

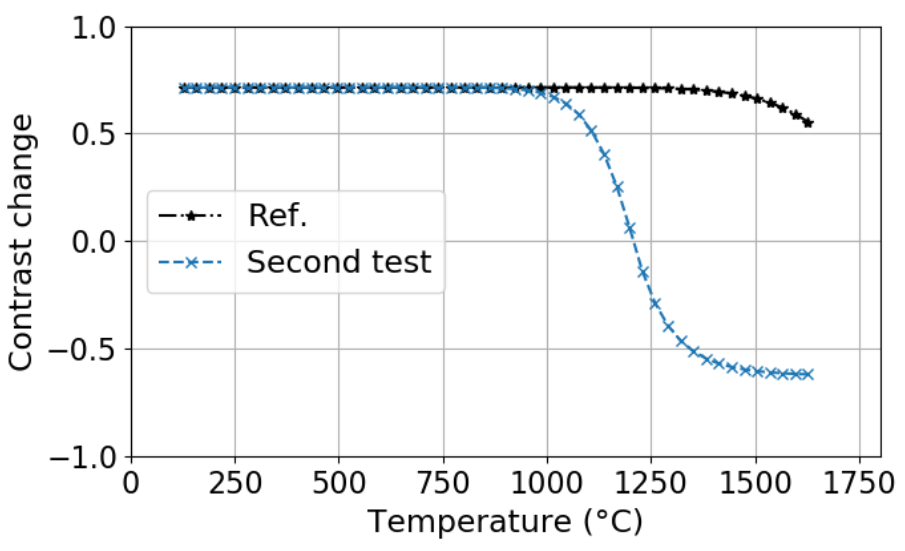

FiguRE 3.10: Description of the inversion of contrast at high temperature

In Figure 3.11 the reference image (a) before heating and the deformed (i.e. during heating) image (b) are shown. Three areas can be distinguished, which confirm, at least qualitatively, the contrast prediction. The first one, far from the laser beam, shows only minor changes to the naked eye even if the EBC seems darker. For the second one, closer to the centre, contrast is virtually lost, thereby preventing any unregularised DIC procedure to be performed. Last, for the area at the highest temperatures, the grey level distribution is inverted (Figure 3.11 (c) and (e)). The EBC, which was initially lighter, becomes darker and the initially black $\mathrm{SiC}$ powder is lighter. Performing registrations between these two 
images would open the way to global DIC up to very high temperatures given the stability of the grey level changes after inversion (Figure 3.10).

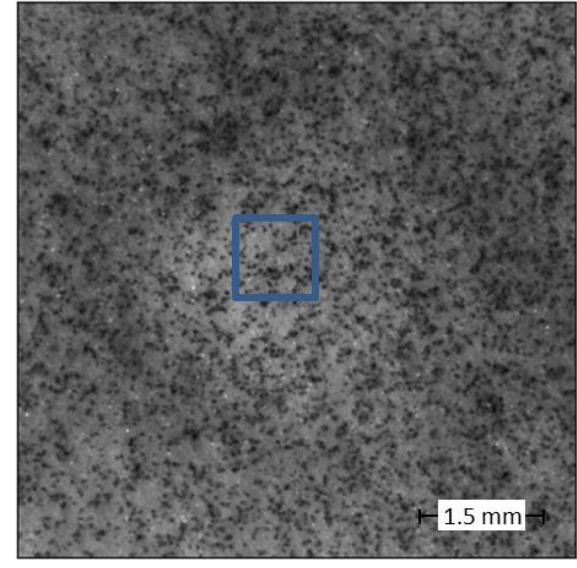

(a)

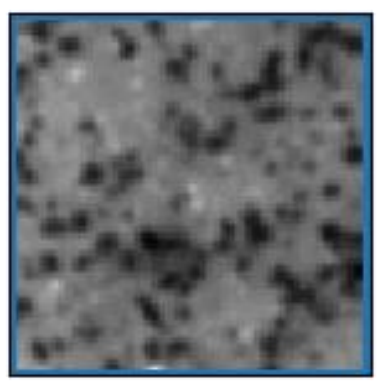

(c)

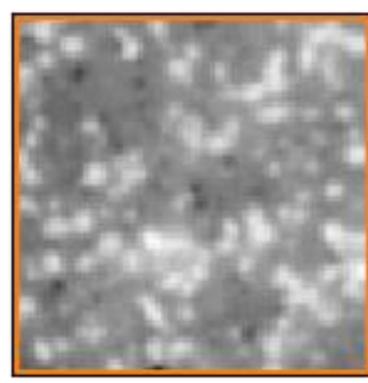

(d)

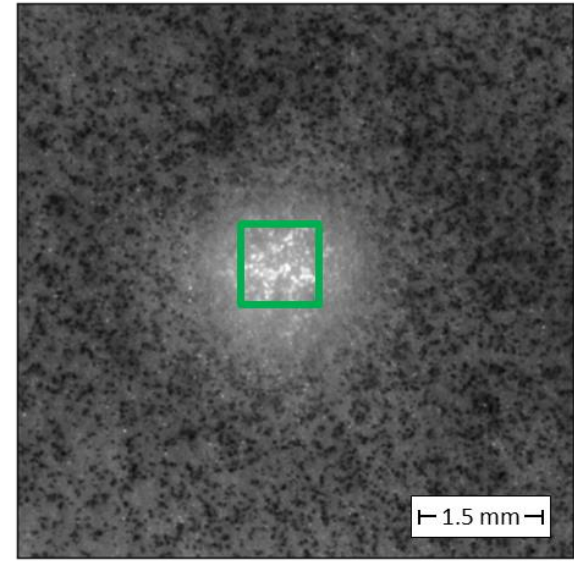

(b)

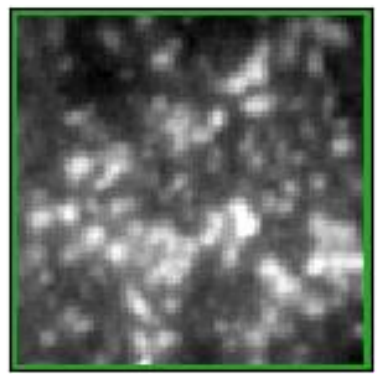

(e)

Figure 3.11: (a) Reference image, (b) heated sample, images of the centre area (c) before heating, (d) before heating and inverted and (e) during heating

Several configurations were tested. Some with the "natural" reference image, some with an artificial inversion $\left(f_{i n v}=\left(2^{n}-1\right)-f\right.$ for a $n$-bit images $)$ of the reference image (Figure 3.11(d)), with either brightness, contrast and brightness, or contrast corrections. In the present case, as the size of the image was very small, displacement fields are not relevant. The objective was to study the influence of the corrections on the grey level residuals. The element size for the 
displacements is $3 \mathrm{px}$. The dynamic range of the reference image is 155 grey levels. The results are summarized in Table 3 and Figure 3.12.

TABLE 3: Influence of corrections on grey level residuals

\begin{tabular}{ccc}
\hline$f$ & Correction & Residuals (\% of \\
& & dynamic range) \\
\hline Reference & Brightness & 22.4 \\
\hline Reference & Contrast & 22.1 \\
\hline Reference & Brightness and contrast & 20.9 \\
\hline Inverted & Brightness & 5.5 \\
\hline Inverted & Contrast & 7.4 \\
\hline Inverted & Brightness and contrast & 7.4 \\
\hline
\end{tabular}

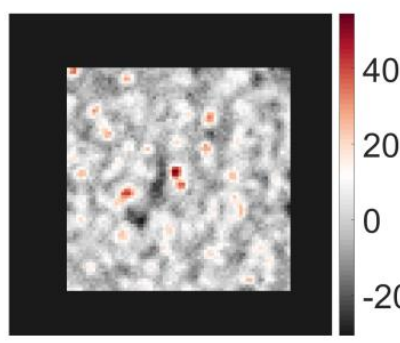

(a)

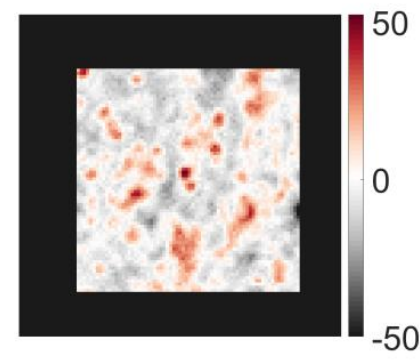

(b)

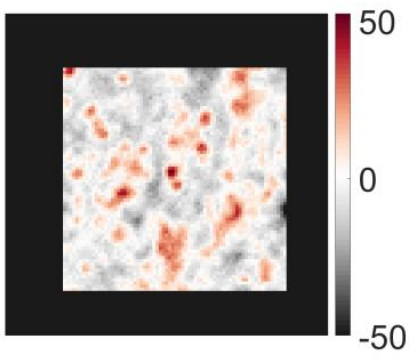

(c)

FIGURE 3.12: Grey level residual fields with (a) brightness correction, (b) contrast correction and (c) brightness and contrast correction

They show the benefit of the artificial inversion on the reference image as the grey level residuals are lower for all corrected cases. Second, for similar reasons as those given in Figure 3.7, the brightness correction exhibited lower residuals than contrast corrections. Besides, these results are explained by the small size of 
the correction mesh (12 px), which makes contrast corrections less secure. In the following, artificial inversion and brightness correction will be used to reach even higher temperatures.

\subsection{Ceramics heated beyond $1500^{\circ} \mathrm{C}$}

In aerospace applications for instance, materials are used at even higher temperatures. Experimental tests performed above $1500^{\circ} \mathrm{C}$ in an open environment represent an additional challenge for DIC as heat haze effects increase significantly. In this section, monolithic ceramics were heated with the same laser and experimental devices described in Section 2. The only difference is the use of a divergent lens to homogenise the laser beam (i.e. the surface temperature field) and prevent the samples from brittle failure. For these cases, the resolution is $14 \mu \mathrm{m} /$ pixel, and the field of view is $28.6 \times 28.6 \mathrm{~mm}^{2}$.

The first test was conducted on the alumina sample. Two levels of heating are presented hereafter. The first one at $1200^{\circ} \mathrm{C}$, and the second one at about $1600^{\circ} \mathrm{C}$. During the first step, two series of images were captured, one with LED lighting and one without any to force contrast inversion. The integration time was adjusted depending on the heating level as described in Table 4.

TABLE 4: Acquisition parameters of the visible light camera

\begin{tabular}{cccc}
\hline $\begin{array}{c}\text { Laser Power } \\
(\mathrm{W})\end{array}$ & Integration time (ms) & Gain (dB) & LED lighting \\
\hline 0 & 22.5 & 0 & Yes \\
\hline 400 & 22.5 & 0 & Yes \\
\hline 400 & 50 & 18 & No \\
\hline 800 & 32 & 0 & No \\
\hline
\end{tabular}


The images are shown in Figure 3.13. At only $1200^{\circ} \mathrm{C}$, the inversion of the grey level distribution occurred (Figure 3.13(d)) by increasing the integration time and gain of the camera. It is worth noting that it gives, at least, a contrast as good as the natural image (Figure 3.13(c)). At higher temperatures, the emissivity of alumina is closer to that of the $\mathrm{SiC}$ powder, which made the inversion of contrast less strong than in the previous case (Figure 3.11 (e)).

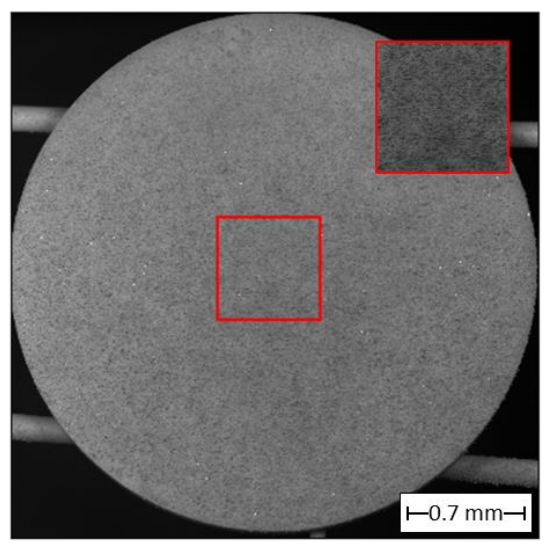

(a)

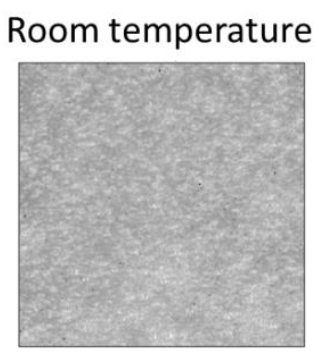

(b)

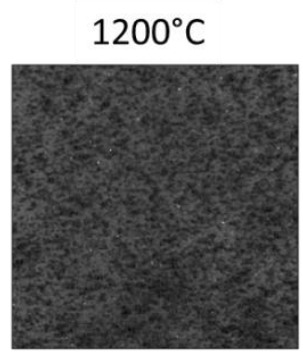

(c)

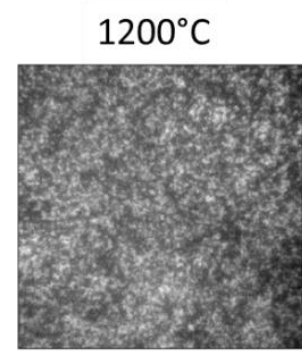

(d) $1600^{\circ} \mathrm{C}$

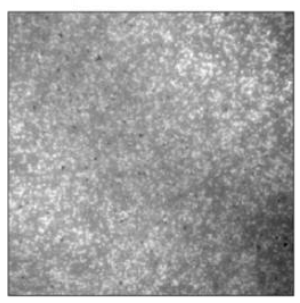

(e)

FIGURE 3.13: (a) Reference image at room temperature, (b) inverted reference image,

(c) image of heated sample with LED lighting, (d) same configuration with no illumination, and (e) last image at $1600^{\circ} \mathrm{C}$

The first heating level was performed to validate DIC using an inversion of contrast. The results with lighting (Figure 3.14), for an element size of $50 \mathrm{px}$, 
show the displacement field in the horizontal direction and the residuals at convergence using brightness correction. Their RMS is 6.7 grey levels, which is rather low for this temperature level. The larger dots are due to a slight overshoot of the fan that had removed some powder.

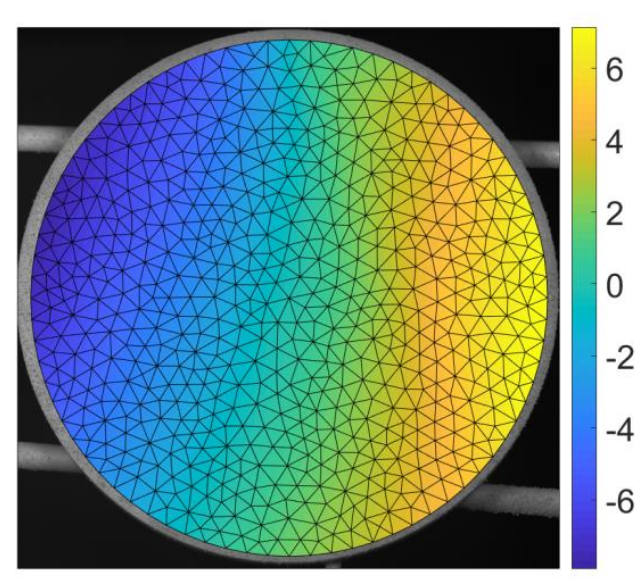

(a)

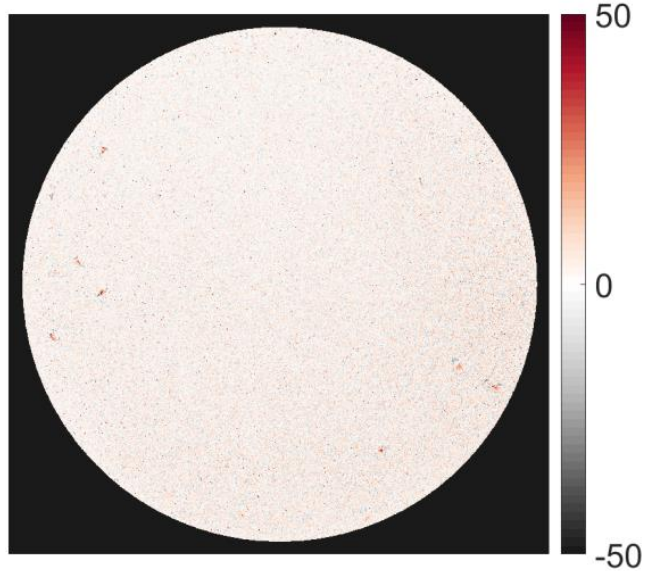

(b)

FIGURE 3.14: (a) Displacement field in the horizontal direction with brightness correction (px), and (b) corresponding grey level residual field

Measurements using contrast inversion are illustrated in Figure 3.15 with (a) the difference on the horizontal displacement with the reference method and (b) the brightness correction. The difference is mostly due to the heat haze effect since the RMS difference is $0.31 \mathrm{px}$ ( $4.4 \%$ of the maximum displacement). These results confirm the possibility of performing DIC using contrast inversion. However, at lower temperatures at which conventional DIC can be used, this method will not be considered because of the large integration time required to invert the image brightness with no illumination. 


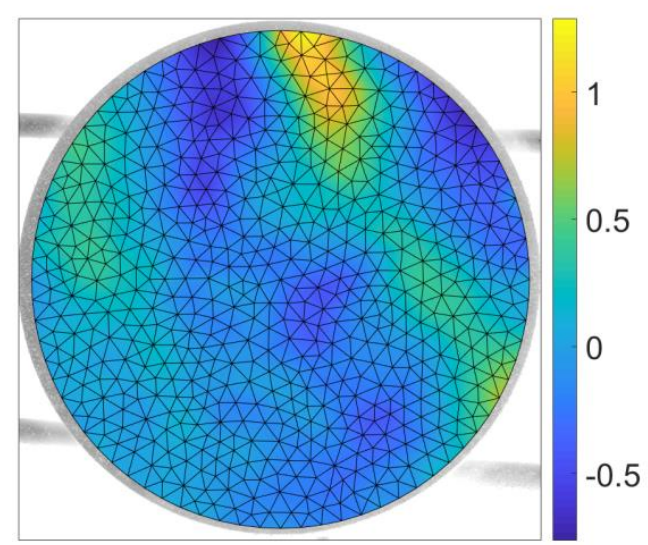

(a)

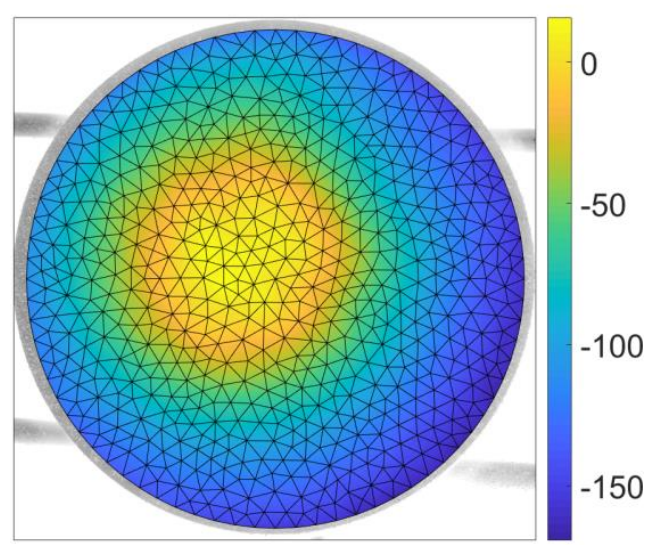

(b)

FIGURE 3.15: (a) Difference in horizontal displacement with reference case (px) and (b) brightness correction field in grey levels

The alumina sample was then heated up to about $1600^{\circ} \mathrm{C}$. Displacement, brightness and residual fields at convergence are shown in Figure 3.16. Once again, the displacement fields were very consistent with thermal expansion. The maximum value for the first step was $6.9 \mathrm{px}$ for the horizontal displacement, and for the second step it was equal to $13.9 \mathrm{px}$. The RMS residual between reference and images of the heated surface is equal to 8.6 grey levels, which is again rather low and validates DIC using inversion of contrast up to very high temperatures. 


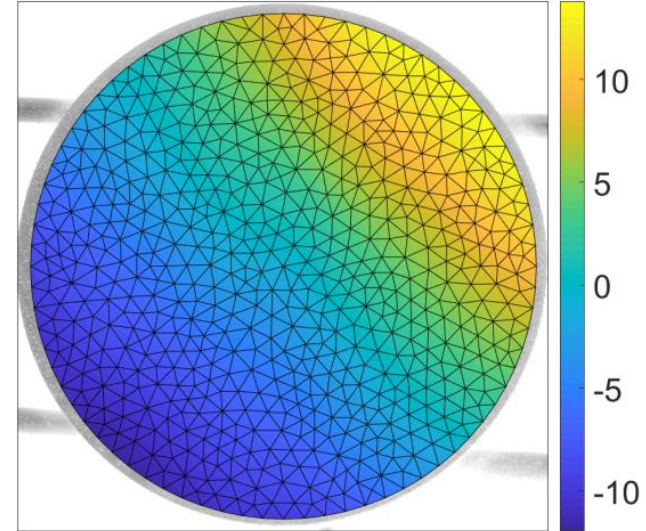

(a)

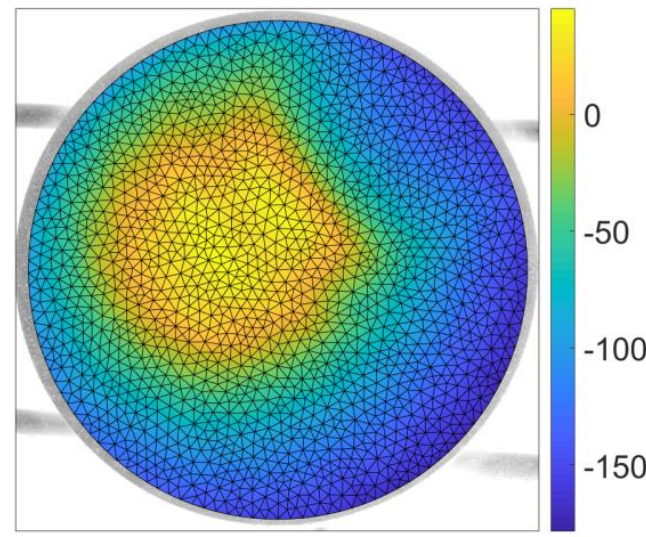

(c)

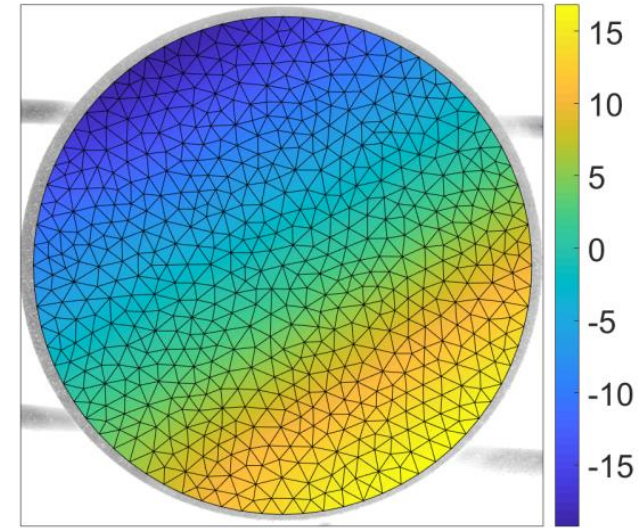

(b)

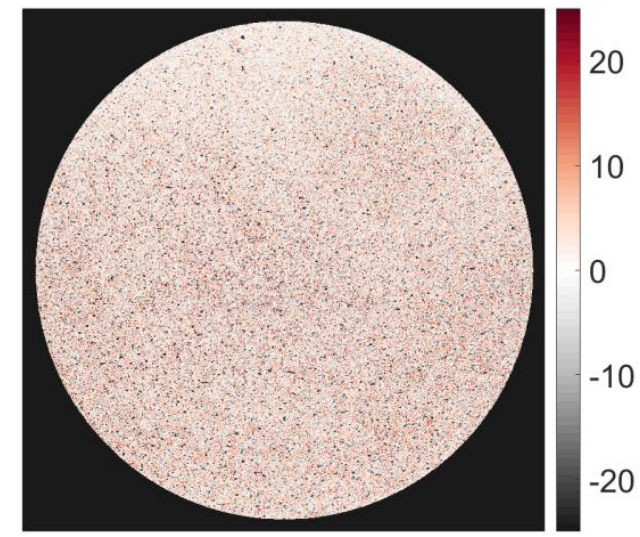

(d)

FIGURE 3.16: (a) Horizontal (b) vertical displacement fields (px), (c) brightness correction field in grey levels, and (d) grey level residual field with a more tightened dynamic

The last test was performed on the Hafnia based sample, which was almost uniformly heated up to $1850^{\circ} \mathrm{C}$. The temperatures were measured using twocolour pyrometers at a wavelength of about $1 \mu \mathrm{m}$. At these wavelengths, the material has the advantage of having a constant emissivity [32], thereby enabling for two-colour pyrometry. The laser power, front-side and back-side temperatures 
are shown in Figure 3.17 (the front side pyrometer delivers meaningful measurements above $1000^{\circ} \mathrm{C}$ ).

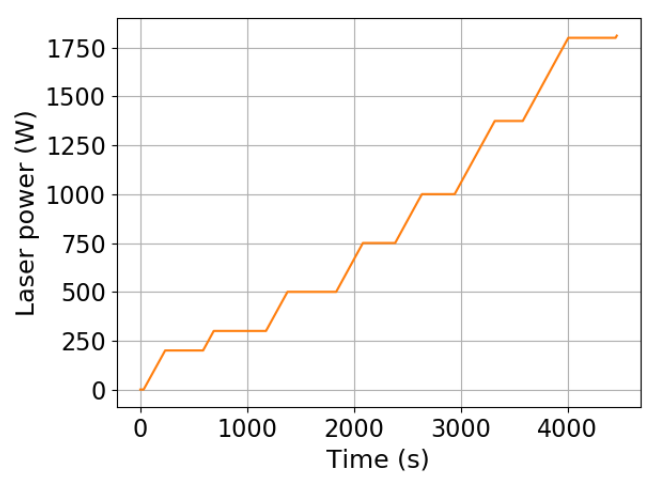

(a)

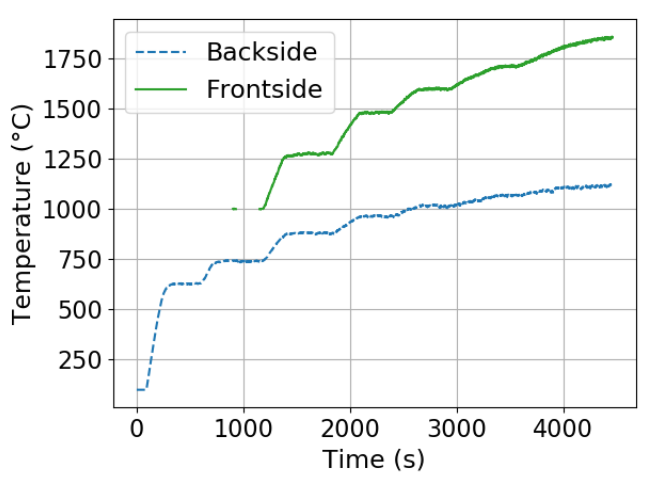

(b)

FiguRE 3.17: (a) Laser power, and (b) front side (in green) and back side (in blue) temperature profiles during the test on hafnia-based sample

The last heating step of the test was analysed with brightness corrections. The size of an element was about $30 \mathrm{px}$ for the displacement and the correction fields. The registered images are shown in Figure 3.18. The inversion was stronger in the centre of the sample because of heat loss on the edges, inducing a thermal gradient. A thin and long crack is visible in Figure 3.18(c). It appears lighter because of higher emissivity.

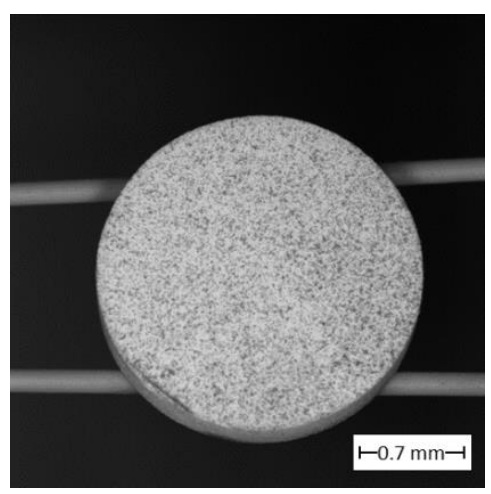

(a)

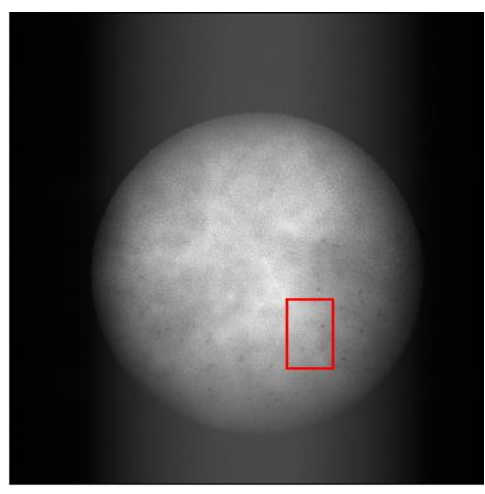

(b)

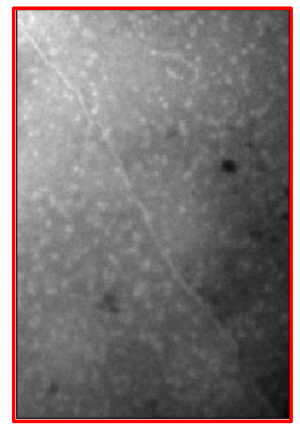

(c) 
FIGURE 3.18: (a) Reference image, (b) image at $1850^{\circ} \mathrm{C}$, and (c) zoom on an area with a crack

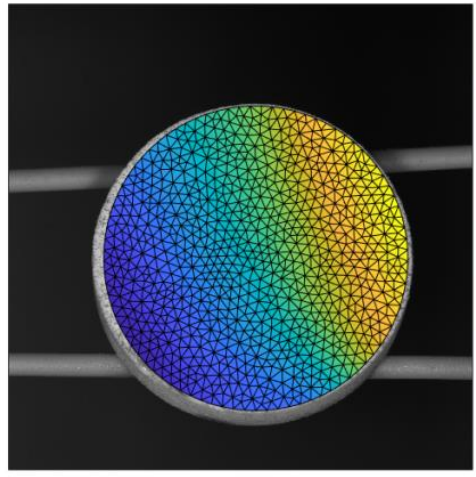

(a)

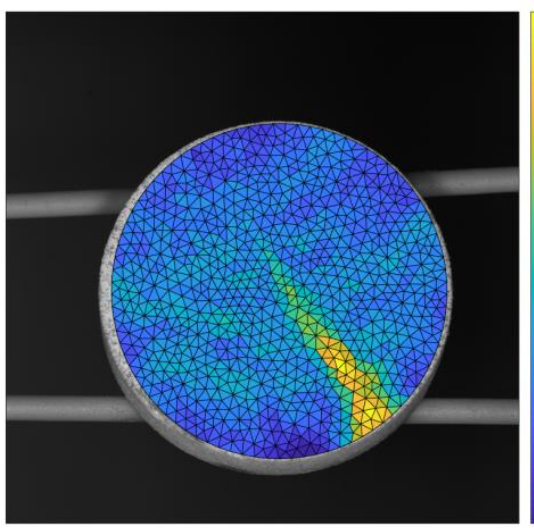

(c)

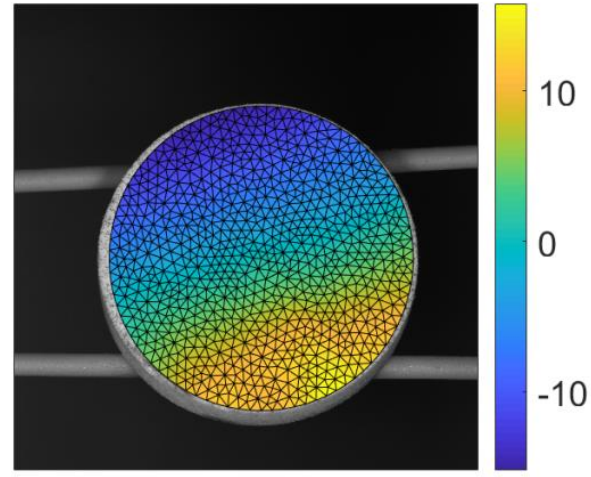

(b)

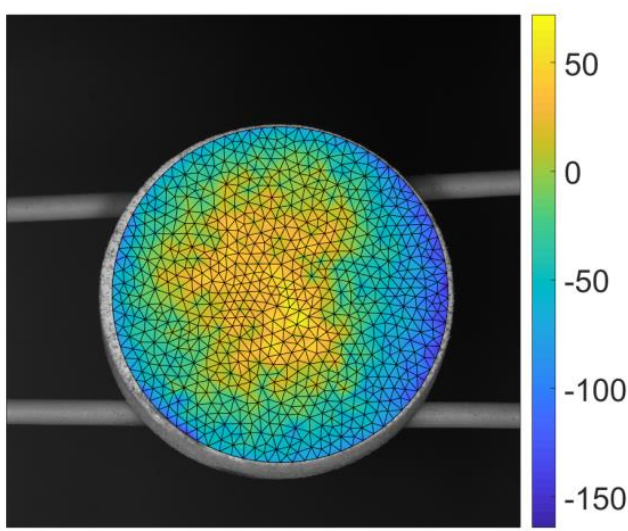

(d) 


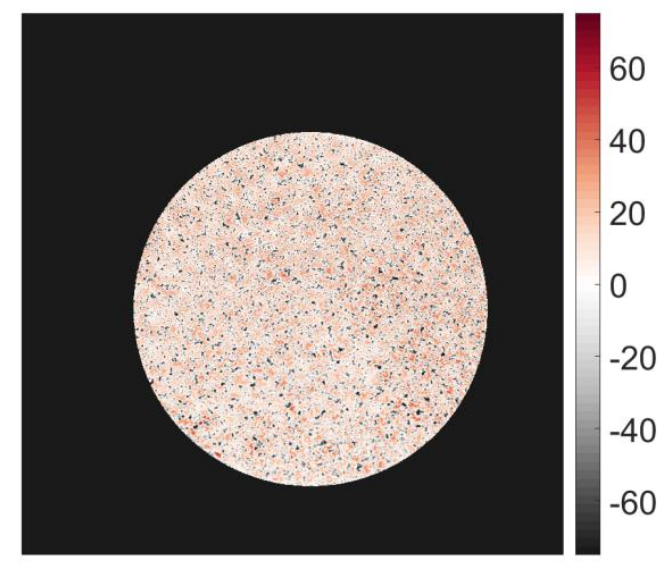

(e)

Figure 3.19: (a) Horizontal, (b) vertical displacement fields (px), (c) maximum positive principal strain field (\%), (d) brightness correction field in grey levels, and (e) grey level residual field

In Figure 3.19, the displacement fields are very smooth, which is consistent with a quasi-uniform heating of the sample. The range of values is close for the horizontal and vertical components. However, the vertical displacement field exhibits high gradients in the bottom right corner. This observation is confirmed with the positive maximum principal strain field, which reveals an over-strain in the same area. This crack is visible in Figure 3.18(c), and starts from the edge up to the centre, which also confirms the shape of the strain field around the crack. The brightness correction is uniform in the centre with lower values near the edges. The RMS residual is equal to 18.3 grey levels. This level is acceptable, especially at these very high temperatures where the stability of the $\mathrm{SiC}$ powder is no longer ensured.

Grey level residuals between images of the cold surface before and after heating, with no correction (Figure 3.20) show that, even though the material brightness remained unchanged, large residuals appear in the powder due to $\mathrm{SiC}$ 
oxidation into silicon dioxide $\left(\mathrm{SiO}_{2}\right)$ over $1400^{\circ} \mathrm{C}$ in dry air. At the end of the test, most of the $\mathrm{SiO}_{2}$ powder had melted on the material surface, which implied local temperatures greater than $1710^{\circ} \mathrm{C}$.

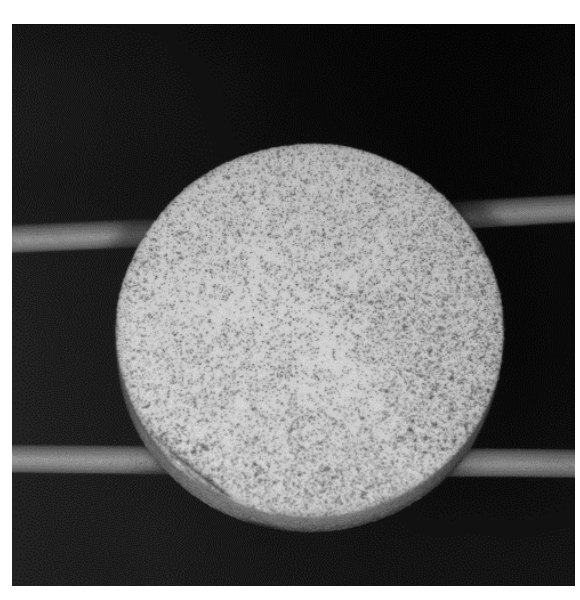

(a)

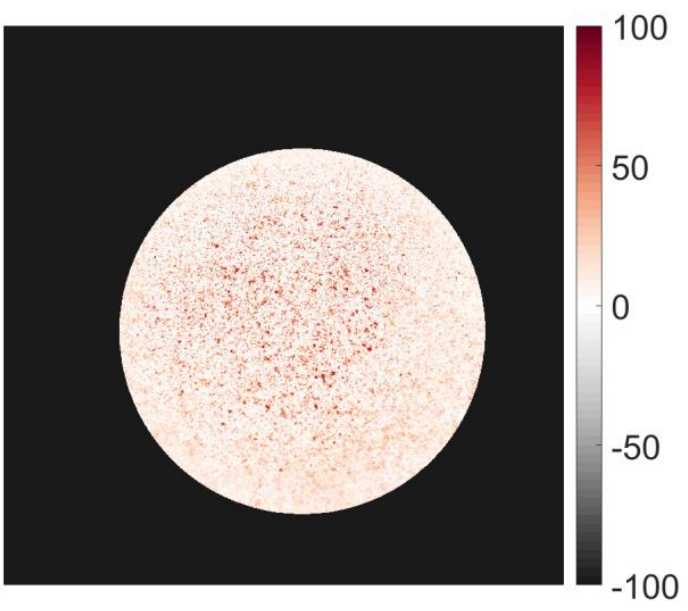

(b)

FIGURE 3.20: (a) Image after the test and (b) grey level residual field with no correction before and after the test

\section{Conclusions and perspectives}

This paper proposed an efficient method for full-field measurements at very high temperatures using global DIC. Thanks to optical filters associated with LED lighting, high quality images were captured up to $1400^{\circ} \mathrm{C}$. The DIC algorithm extracted very reliable displacement fields with low residuals thanks to grey level corrections. For higher temperatures, instead of shifting the devices to shorter wavelengths and more powerful LED lighting, illumination was no longer required to invert the room temperature contrast. Results of this work showed the reliability of DIC up to $1850^{\circ} \mathrm{C}$ on a hafnia-based sample with the detection of a thin crack, and rather low grey level residuals. It is worth noting that the 
temperature limitation is only linked to the stability of the material and the powder.

This work opens the route of characterisations at temperatures at which information was hardly accessible, especially via full-field measurements. For instance, coefficients of thermal expansion of the hafnia-based material could be estimated using finite element model updating (required in case of 3D thermal gradients and properties depending on temperature). As these materials are to be used as protective coatings, it is a key property.

As introduced in this work, grey level relaxation (mainly brightness corrections) was used to measure temperature fields. In all the studied cases, the shape of the brightness field was consistent with the thermal loading, be it almost uniform or Gaussian-distributed. A calibration procedure without speckle on the material surface, with the knowledge of the emissivity and an infrared camera, may allow for such measurements as already shown for near infrared cameras [15], but this time at much higher temperature levels.

\section{Acknowledgements}

This work was supported under PRC MECACOMP, a French research project co-funded by DGAC and SAFRAN Group, managed by SAFRAN Group and involving SAFRAN Group, ONERA and CNRS. 


\section{References}

[1] G. N. Morscher, "Tensile creep and rupture of 2D-woven $\mathrm{SiC} / \mathrm{SiC}$ composites for high temperature applications », J. Eur. Ceram. Soc., vol. 30, $n^{\circ} 11$, p. 2209-2221, 2010.

[2] M. P. Appleby, D. Zhu, et G. N. Morscher, « Mechanical properties and real-time damage evaluations of environmental barrier coated $\mathrm{SiC} / \mathrm{SiC}$ CMCs subjected to tensile loading under thermal gradients », Surf. Coat. Technol., vol. 284, p. 318-326, 2015.

[3] A. Burr, F. Hild, et F. A. Leckie, « The behavior of ceramic-matrix composites under thermo-mechanical cyclic conditions», Compos. Sci. Technol., vol. 58, no 5, p. 779-783, 1998.

[4] M. Berny, T. Archer, A. Mavel, P. Beauchêne, S. Roux, et F. Hild, « On the analysis of heat haze effects with spacetime DIC », Opt. Lasers Eng., vol. 111, p. 135-153, 2018.

[5] Michel Grédiac et F. Hild, Full-field measurements and identification in solid mechanics. Jonh Wiley \& Sons, 2012.

[6] M. A. Sutton, J. J. Orteu, et H. Schreier, Image correlation for shape, motion and deformation measurements: basic concepts, theory and applications. Springer Science \& Business Media, 2009.

[7] J. S. Lyons, J. Liu, et M. A. Sutton, « High-temperature deformation measurements using digital-image correlation », Exp. Mech., vol. 36, nº 1, p. 64-70, 1996.

[8] J. Liu, J. Lyons, M. Sutton, et A. Reynolds, « Experimental Characterization of Crack Tip Deformation Fields in Alloy 718 at High Temperatures », J. Eng. Mater. Technol., vol. 120, nº 1, p. 71, 1998.

[9] B. Pan, D. Wu, Z. Wang, et Y. Xia, « High-temperature digital image correlation method for full-field deformation measurement at $1200 \mathrm{C} »$, Meas. Sci. Technol., vol. 22, no 1, p. 015701, 2010.

[10] B. M. B. Grant, H. J. Stone, P. J. Withers, et M. Preuss, « Hightemperature strain field measurement using digital image correlation », $J$. Strain Anal. Eng. Des., vol. 44, no 4, p. 263-271, 2009.

[11] P. Leplay, O. Lafforgue, et F. Hild, « Analysis of Asymmetrical Creep of a Ceramic at $1350^{\circ} \mathrm{C}$ by Digital Image Correlation », J. Am. Ceram. Soc., vol. 98, no 7, p. 2240-2247, 2015.

[12] M. D. Novak et F. W. Zok, « High-temperature materials testing with fullfield strain measurement: Experimental design and practice», Rev. Sci. Instrum., vol. 82, $\mathrm{n}^{\circ}$ 11, p. 115101, 2011.

[13] W. Wang, C. Xu, H. Jin, S. Meng, Y. Zhang, et W. Xie, « Measurement of high temperature full-field strain up to $2000{ }^{\circ} \mathrm{C}$ using digital image correlation », Meas. Sci. Technol., vol. 28, nº 3, p. 035007, 2017. 
[14] R. B. Berke et J. Lambros, « Ultraviolet digital image correlation (UV-DIC) for high temperature applications », Rev. Sci. Instrum., vol. 85, $\mathrm{n}^{\circ} 4$, p. 045121, 2014.

[15] A. Maynadier, M. Poncelet, K. Lavernhe-Taillard, et S. Roux, « One-shot Measurement of Thermal and Kinematic Fields: InfraRed Image Correlation (IRIC) », Exp. Mech., vol. 52, n 3, p. 241-255, 2012.

[16] A. Charbal et al., «Integrated Digital Image Correlation considering gray level and blur variations: Application to distortion measurements of IR camera », Opt. Lasers Eng., vol. 78, p. 75-85, 2016.

[17] G. Besnard, F. Hild, et S. Roux, «"Finite-Element" Displacement Fields Analysis from Digital Images: Application to Portevin-Le Châtelier Bands », Exp. Mech., vol. 46, nº 6, p. 789-803, 2006.

[18] F. Hild et S. Roux, " Comparison of Local and Global Approaches to Digital Image Correlation », Exp. Mech., vol. 52, no 9, p. 1503-1519, 2012.

[19] F. Hild et S. Roux, « Digital Image Correlation », in Optical Methods for Solid Mechanics. A Full-Field Approach, Wiley-VCH, 2012, p. 183-228.

[20] A. Charbal, S. Roux, F. Hild, et L. Vincent, "Regularised digital-level corrections for infrared image correlation », Quant. InfraRed Thermogr. J., p. 1-22, 2018

[21] M. P. Boyce, Gas turbine engineering handbook. Elsevier, 2011.

[22] P. P. Walsh et P. Fletcher, Gas turbine performance, 2nd ed. Malden, MA: Blackwell Science, 2004.

[23] J. A. DiCarlo, H.-M. Yun, G. N. Morscher, et R. T. Bhatt, « SiC/SiC Composites for $1200^{\circ} \mathrm{C}$ and Above », in Handbook of Ceramic Composites, N. P. Bansal, Éd. Springer US, 2005, p. 77-98.

[24] A. G. Evans et D. B. Marshall, « The mechanical behavior of ceramic matrix composites », Acta Metall., vol. 37, no 10, p. 2567-2583, 1989.

[25] L. Sévin, A. Julian-Jankowiak, J. F. Justin, C. Langlade, P. Bertrand, et N. Pelletier, «Structural Stability of Hafnia-Based Materials at Ultra-High Temperature », Mater. Sci. Forum, vol. 941, p. 1972-1977, 2018.

[26] Y. L. Dong et B. Pan, «A Review of Speckle Pattern Fabrication and Assessment for Digital Image Correlation », Exp. Mech., vol. 57, $\mathrm{n}^{\circ}$ 8, p. 1161-1181, 2017.

[27] R. Degeilh, « Développement expérimental et modélisation d'un essai de fatigue avec gradient thermique de paroi pour application aube de turbine monocristalline », Ecole normale supérieure de Cachan, 2013.

[28] A. Mendoza, J. Schneider, E. Parra, E. Obert, et S. Roux, « Differentiating 3D textile composites: A novel field of application for Digital Volume Correlation », Compos. Struct., vol. 208, p. 735-743, 2019. 
[29] F. Mathieu, H. Leclerc, F. Hild, et S. Roux, «Estimation of Elastoplastic Parameters via Weighted FEMU and Integrated-DIC », Exp. Mech., vol. 55, $\mathrm{n}^{\circ}$ 1, p. 105-119, 2015.

[30] H. Leclerc, J. Neggers, F. Mathieu, F. Hild, et S. Roux, « Correli 3.0, IDDN. FR. 001.520008. 000. SP 2015.000. 31500», Agence pour la Protection des Programmes Paris (France), 2015.

[31] N. E. Massa et al., « High temperature emissivity, reflectivity, and x-ray absorption of BiFeO3 », J. Appl. Phys., vol. 108, nº 8, p. 084114, 2010.

[32] L. del Campo et al., " High-Temperature Radiative Properties of an YttriaStabilized Hafnia Ceramic: High Temperature Radiative Properties of an YSH Ceramic », J. Am. Ceram. Soc., vol. 94, nº 6, p. 1859-1864, 2011.

[33] G. Neuer et G. Jaroma-Weiland, «Spectral and Total Emissivity of HighTemperature Materials », Int. J. Thermophys., vol. 19, $\mathrm{n}^{\circ}$ 3, p. 917-929, 1998. 